\title{
SOME STUDIES ON STRENGTH BEHAVIOR OF RECYCLED AGGREGATE CONCRETE
}

\author{
Shivanand ${ }^{1}$, H.S. Vidyadhar ${ }^{2}$ \\ ${ }^{I}$ M. Tech Scholar, Department of Civil Engineering, PDA College of Engineering, Kalaburagi, VTU, Karnataka, India \\ ${ }^{2}$ Professor, Department of Civil Engineering, PDA College of Engineering, Kalaburagi, VTU, Karnataka, India
}

\begin{abstract}
This dissertation work deals with the study of compressive strength behavior of Recycled Aggregate Concrete. Increase in population growth is leading to increase in various demands like cultivation, transportation, construction etc. Now a day's, a tremendous increase in the demand for construction works like residential buildings, bridges, dams, roads etc. Because of this increase in demand, the availability in the sources of concrete ingredients is getting difficult. Hence people are looking for alternative sources for the concrete ingredients in order to fulfill their requirements.
\end{abstract}

Crushing the concrete debris by suitable means, R.C.A and R.F.A can be removed from the parental concrete and after proper sieving, they can be made use in new construction work. In this ongoing project work it is concentrated only on use of R.C.A.. The main object in this investigation is to find out upto what percentage the N.C.A can be replaced by R.C.A in the concrete mix and to find out the extra quantity of cement to be added for each percentage replacement by R.C.A, to achieve its target mean strength.

\section{INTRODUCTION}

Recycled Aggregates are comprised of crushed, graded inorganic particles processed from the materials that have been used in the construction and demolition debris. The aim of this on-going project work is to determine the compressive strength characteristic of recycled aggregates for application in high strength structural concrete, which will give a better understanding on the properties of concrete with recycled aggregates as an alternative material to coarse aggregate in structural concrete.

Strong need was felt of utmost importance to evolve suitable means to reuse the huge amount of rubble or rubbish obtained from the crushed buildings and structures due to bombardment during and just after the Second World War.

The reuse of the waste rubble of masonry and concrete was given prime importance rather than dumping elsewhere, which may said to be governed by two main considerations viz. the paucity of large dumping yard for accommodating such huge volume of waste materials and the nonavailability or very high cost of the fresh materials of construction due to the shattered economy suffered from the war.

In R.A.C. the big particles from the crushed rubbles properly screened to size form the coarse aggregate part, whereas the finer particles processed similarly serve the fine aggregate part, though the making of concrete from the R.A and that from the N.A commonly termed as original concrete or conventional concrete do not differ at all so far the procedure is concerned, the R.A do so from the original aggregate (O.A) in that the former is always surrounded by the particles of the old mortar, which influence a good deal of change in the physical properties of the aggregates. This aspect of R.A is reflected on the strength of R.A.C.
However if the reduction of the strength from the R.A.C in comparison to that of the N.A.C is tolerated to an acceptable degree, there is no reason why the said concept could not be extended for other standard structural day to day use.

Due to the enormous developmental work and great increase in the construction of the concrete structures, there is a large demand for the good quality of natural aggregates. Due to this large demand and decrease in the supply it has become necessary to search for other sources for procuring aggregates. A recent survey conducted by Environmental Resource Limited estimated that, 80 million tones of demolition wastes arise from reconstruction in European Economic Countries each year.

The total experimental investigations involved in this project work have been divided into three different phases. The details of the work allotted to each phase in given below:

\section{PHASE 1}

Sufficient amount of R.A is needed for the entire investigation for this project. Also it is necessary to know the physical and mechanical properties of Recycled Aggregates for the concrete mix design to perform with these data.

Hence in the phase-1, work has been carried out in the following steps:

1) Carrying out of the all the preliminary work such as testing of cement, aggregate, sand etc.

2) Production of Recycled Aggregates in sufficient amount needed for the entire work of the mix design.

3) Experimental investigation for getting of the various physical and mechanical properties of the Recycled Aggregates obtained thereof. 


\subsection{Preliminary Tests on Ingredients of Original}

\section{Concrete}

Before starting the actual project work, it is necessary to know various properties of concrete ingredients, to assess their quality and suitability. Hence various preliminary tests have been conducted on cement, natural aggregates, natural sand etc.

\subsubsection{Tests on Cement}

Cement used is of 53 grade Ordinary Portland Cement (OPC), the results of various preliminary tests conducted on this cement are as given in table. 2.1 below:

Table 2.1: Preliminary tests results of Cement.

\begin{tabular}{|l|l|l|}
\hline 1 & Normal consistency & $31 \%$ \\
\hline 2 & Initial setting time & $1: 15 \mathrm{~min}$ \\
\hline 3 & Final setting time & $2: 23 \mathrm{~min}$ \\
\hline 4 & Specific gravity & 2.954 \\
\hline 5 & Soundness & $1 \mathrm{~mm} \mathrm{exp}$ \\
\hline 6 & $\begin{array}{l}\text { Compressive strength of } \\
\text { cement for 28-days curing }\end{array}$ & $47.28 \mathrm{~N} / \mathrm{mm}^{2}$ \\
\hline
\end{tabular}

\subsubsection{Tests on Natural Coarse Aggregates}

The N.C.A used here are of $20 \mathrm{~mm}$ down size. Preliminary tests such as water absorption, moisture content, sieve analysis, specific gravity and crushing strength tests have carried out and the results are as given in table 2.2 below.

Table 2.2: Preliminary tests results of N.C.A.

\begin{tabular}{|l|l|l|}
\hline 1 & Water absorption & $0.8 \%$ \\
\hline 2 & Moisture content & $0.806 \%$ \\
\hline 3 & Specific gravity & 2.727 \\
\hline 4 & Crushing strength & $16.07 \%$ \\
\hline 5 & Flakiness index & $19.60 \%$ \\
\hline 6 & Elongation index & $20.60 \%$ \\
\hline
\end{tabular}

The tables showing the details regarding sieve analysis and shape test of C.A are been given in table 2.1 and table 2.2 respectively under chapter 4 .

\subsubsection{Tests on Fine Aggregate}

The source for fine aggregate used is from natural river bed, the details regarding preliminary test conducted on it are as given in table 2.3 below.

Table 2.3: Preliminary Tests results of N.F.A.

\begin{tabular}{|l|l|l|}
\hline 1 & Moisture content & $2.0 \%$ \\
\hline 2 & Water absorption & $1.20 \%$ \\
\hline 3 & Specific gravity & 2.56 \\
\hline 4 & Sieve analysis & $\begin{array}{l}\text { Zone } \\
\text { II }\end{array}$ \\
\hline
\end{tabular}

\section{PHASE 2}

Based on the results obtained by the preliminary tests conducted on the various ingredients of O.C, suitable mix design for M20-grade plane concrete under mild exposure condition is designed.

\subsection{Concrete Mix Design}

Concrete mix design is been carried out as per IS-code method.

\subsection{Casting and Testing Work}

Considering the data's in terms of concrete ingredient proportions as per IS-method of mix design, cubes of dimension $150 \mathrm{~mm} \times 150 \mathrm{~mm} \times 150 \mathrm{~mm}$ are casted.

These cubes are kept immersed in water for 28-days curing, thereafter tested for their compressive strength under compression testing machine.

\subsection{Source for Recycled Aggregate Concrete}

One's the compressive strength testing is over, the cubes are broken in to pieces by using hammer and the C.A are separated from it. Obtained C.A are sieved under $20 \mathrm{~mm}$ sieve (passing) and $4.75 \mathrm{~mm}$ sieve (retained), latter these aggregates are used as R.C.A for further work. Details regarding sieve analysis of R.C.A are done.

\subsubsection{Preliminary Tests Conducted on Recycled}

\section{Coarse Aggregates}

After obtaining the R.C.A from original concrete cubes, preliminary tests such as sieve analysis, water absorption, moisture content, specific gravity and crushing strength have been carried out.

Table 2.4: Preliminary tests results of R.C.A.

\begin{tabular}{|l|l|l|}
\hline 1 & Moisture content & $3.3 \%$ \\
\hline 2 & Water absorption & $3.0 \%$ \\
\hline 3 & Specific gravity & $2.5 \%$ \\
\hline 4 & Crushing strength & $19.64 \%$ \\
\hline
\end{tabular}

\subsection{Compressive Strength}

The compressive strength obtained by the above mix design for M20 grade concrete after 28-days of curing was 52.252 $\mathrm{N} / \mathrm{mm} 2$, which is a higher value than its target mean strength (26.6 N/mm2). Hence considering economy as a factor, mix design with higher $\mathrm{W} / \mathrm{C}$ ratio is been proposed. As the $\mathrm{W} / \mathrm{C}$ ratio increase, cement quantity will get decrease and hence the concrete mix becomes economical, thereafter it is checked for its compressive strength. Mix design for higher $\mathrm{W} / \mathrm{C}$ ratios viz. $0.55,0.57$ and $0 / 59$ is been done.

For each of above mix design, cubes of dimension 150mm x $150 \mathrm{~mm} \times 150 \mathrm{~mm}$ are casted in three numbers for each mix and kept under water for 7-days curing. 
After 7-days of curing, cubes are tested for their compressive strength under compression testing machine.

By the obtained results it has been observed that, for W/C ratio of 0.59 the compressive strength attained after 7-days of curing was $70 \%$ of target mean strength, hence it has been chosen for further work.

\section{Difference between the Properties of N.C.A and R.C.A}

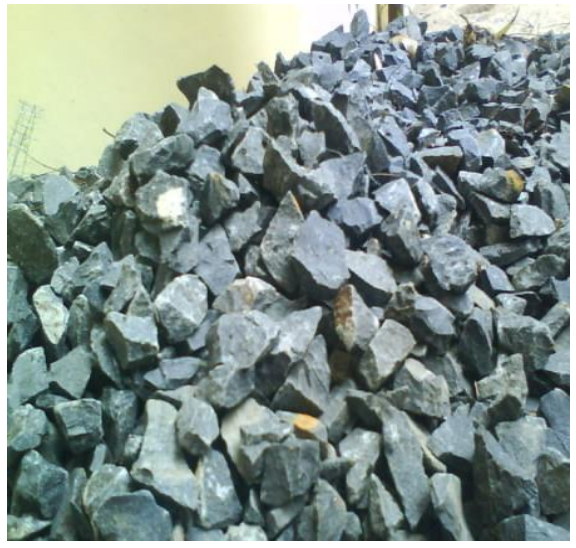

Fig 3.1(a) : N.C.A

\subsection{Concrete Mix Design based on the Properties of} Recycled Coarse Aggregates

Considering the preliminary tests results conducted on R.C.A, concrete mix design for M20-grade under mild exposure condition with W/C ratio of 0.59 is been designed.

Based on the preliminary tests conducted on N.C.A and R.C.A, some of the differences between their properties are been given in table 3.5 below.

Table 3.5: Difference between N.C.A and R.C.A.

\begin{tabular}{|l|l|l|l|l|l|}
\hline $\begin{array}{l}\text { Type of } \\
\text { aggregate }\end{array}$ & Physical appearance & $\begin{array}{l}\text { Moisture } \\
\text { content }(\boldsymbol{\%})\end{array}$ & $\begin{array}{l}\text { Water } \\
\text { absorption }(\boldsymbol{\%})\end{array}$ & $\begin{array}{l}\text { Specific } \\
\text { gravity }\end{array}$ & $\begin{array}{l}\text { Crushing } \\
(\%)\end{array}$ \\
\hline N.A & $\begin{array}{l}\text { Smooth texture with angular } \\
\text { surface }\end{array}$ & 0.806 & 0.80 & 2.727 & 16.07 \\
\hline RA. & $\begin{array}{l}\text { Rough texture with angular } \\
\text { and elongated surface }\end{array}$ & 3.3 & 3.0 & 2.5 & 19.64 \\
\hline
\end{tabular}

\section{PHASE 3}

In this phase, work is once again divided into two parts as follows.

Part 1: Casting work is carried out based on the N.C.A properties in the concrete mix design.

Part 2: Casting work is carried out based on the co-related quantities of concrete ingredients between N.CA and R.C.A properties in the concrete mix design. Above mentioned works are explained in details as follows.

\subsection{Part 1: Casting Work Based on the N.C.A}

\section{Properties}

Using the concrete mix design for M20-grade under mild exposure condition based on N.C.A properties, cubes of dimension $150 \mathrm{~mm} \times 150 \mathrm{~mm} \times 150 \mathrm{~mm}$ are casted.

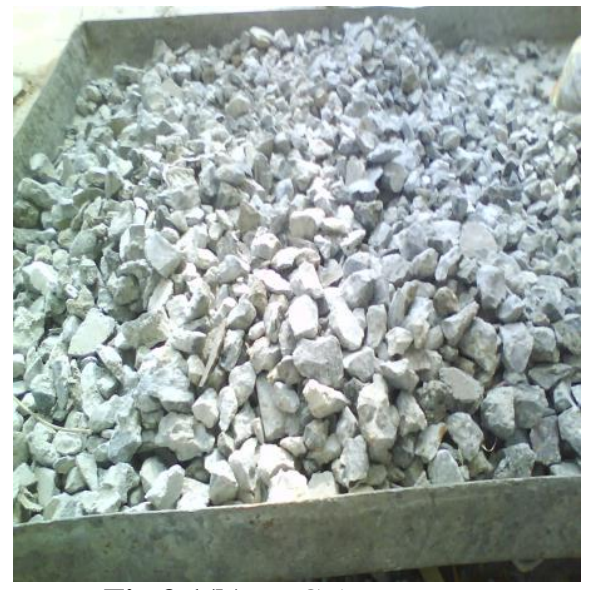

Fig 3.1(b): R.C.A 
Table 3.6: Quantities of concrete ingredients in all six concrete mixes using N.C.A properties

\begin{tabular}{|c|c|c|c|c|c|c|c|}
\hline \multirow[b]{2}{*}{ Mix No. } & \multirow{2}{*}{$\begin{array}{l}\text { Num of } \\
\text { Cubes }\end{array}$} & \multirow{2}{*}{ W/C } & \multirow{2}{*}{$\begin{array}{l}\text { Cement } \\
(\mathrm{kg})\end{array}$} & \multirow{2}{*}{$\begin{array}{l}\text { Water } \\
\text { (Ltr) }\end{array}$} & \multirow{2}{*}{$\begin{array}{l}\text { N.F.A } \\
\text { (kg) }\end{array}$} & \multicolumn{2}{|l|}{ C.A. } \\
\hline & & & & & & N.C.A.(Kg) & R.C.A.(Kg) \\
\hline 1. & 06 & 0.59 & 7.77 & 4.56 & 15.2 & 29.30 & 0.0 \\
\hline 2. & 06 & 0.59 & 7.77 & 4.56 & 15.2 & 23.44 & 5.90 \\
\hline 3. & 06 & 0.59 & 7.77 & 4.56 & 15.2 & 17.58 & 11.72 \\
\hline 4. & 06 & 0.59 & 7.77 & 4.56 & 15.2 & 11.72 & 17.58 \\
\hline 5 . & 06 & 0.59 & 7.77 & 4.56 & 15.2 & 5.90 & 23.44 \\
\hline 6. & 06 & 0.59 & 7.77 & 4.56 & 15.2 & 0.0 & 29.30 \\
\hline
\end{tabular}

These cubes care kept immersed in water for curing and later they are tested for their compressive strength after 7days and 28-days of curing.

\subsection{Part-2 Casting Work Based on the Correlated} Quantities of Concrete Ingredients between the

\section{N.C.A and R.C.A}

Quantities of the concrete ingredients which are obtained based on N.C.A and R.CA are been co-related with each other.
Using the material quantities obtained after correlation, cubes of dimension $150 \mathrm{~mm} \times 150 \mathrm{~mm} \times 150 \mathrm{~mm}$ are casted. Here also, six different mixes are made and in each mix the N.C.A are replaced by R.C.A by $20 \%$ i.e., in the $1^{\text {st }}$ mix $100 \%$ N.C.A are used in concrete mix were as in $2^{\text {nd }}, 3^{\text {rd }}, 4^{\text {th }}$ and $5^{\text {th }}$ mix $20 \%, 40 \%, 60 \%$ and $80 \%$ replacement of N.C.A by R.CA is made. In the final $6^{\text {th }}$ mix N.C.A are replaced $100 \%$ by R.C.A.

The material quantities that are used in above six mixes are given in table no. 3.7 below.

Table 3.7: Quantities of concrete ingredients after correlating between the N.C.A and R.C.A properties.

\begin{tabular}{|c|c|c|c|c|c|c|c|}
\hline \multirow{2}{*}{$\begin{array}{l}\text { Mix } \\
\text { No. }\end{array}$} & \multirow{2}{*}{$\begin{array}{l}\begin{array}{l}\text { Num of } \\
\text { Cubes }\end{array} \\
\end{array}$} & \multirow{2}{*}{ W/C } & \multirow{2}{*}{$\begin{array}{l}\text { Cement } \\
(\mathrm{kg})\end{array}$} & \multirow{2}{*}{$\begin{array}{l}\text { Water } \\
\text { (Ltr) }\end{array}$} & \multirow{2}{*}{$\begin{array}{l}\text { N.F.A } \\
\text { (kg) }\end{array}$} & \multicolumn{2}{|l|}{ C.A. } \\
\hline & & & & & & N.C.A.(Kg) & R.C.A.(Kg) \\
\hline 1. & 06 & 0.59 & 7.77 & 4.56 & 15.20 & 29.30 & 0.00 \\
\hline 2. & 06 & 0.59 & 7.98 & 4.662 & 15.20 & 22.90 & 5.76 \\
\hline 3. & 06 & 0.59 & 8.136 & 4.78 & 15.20 & 16.80 & 11.20 \\
\hline 4. & 06 & 0.59 & 8.28 & 4.90 & 15.20 & 10.96 & 16.60 \\
\hline 5. & 06 & 0.59 & 8.50 & 5.0 & 15.20 & 5.35 & 21.42 \\
\hline 6. & 06 & 0.59 & 8.68 & 5.122 & 15.20 & 0.00 & 26.2 \\
\hline
\end{tabular}

Prepared cubes are kept immersed under water and they are tested for their compressive strength after 7-days and 28days of curing.

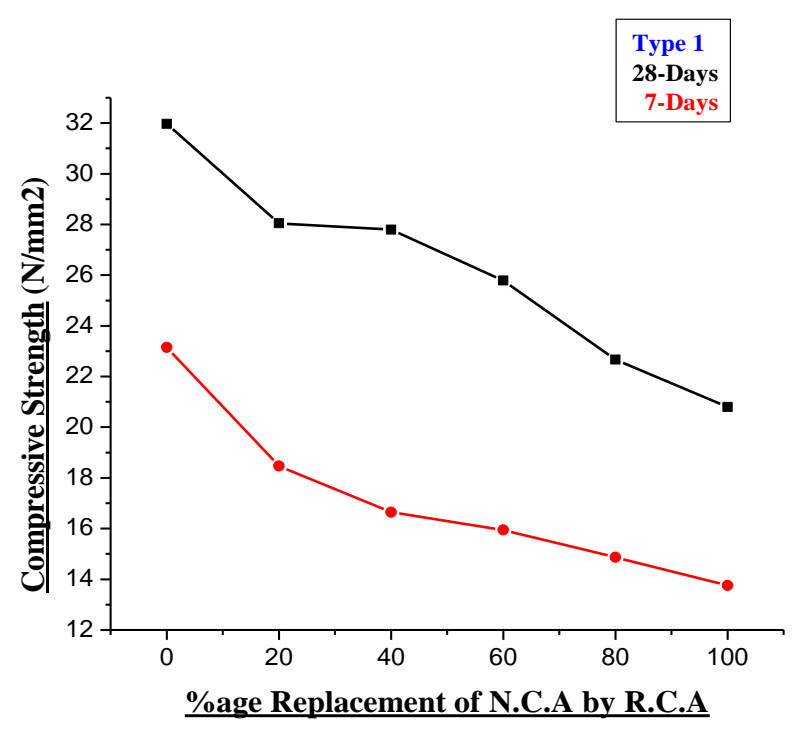

Fig 4.4: \% Replacement of N.C.A by R.C.A V/S Compressive Strength.

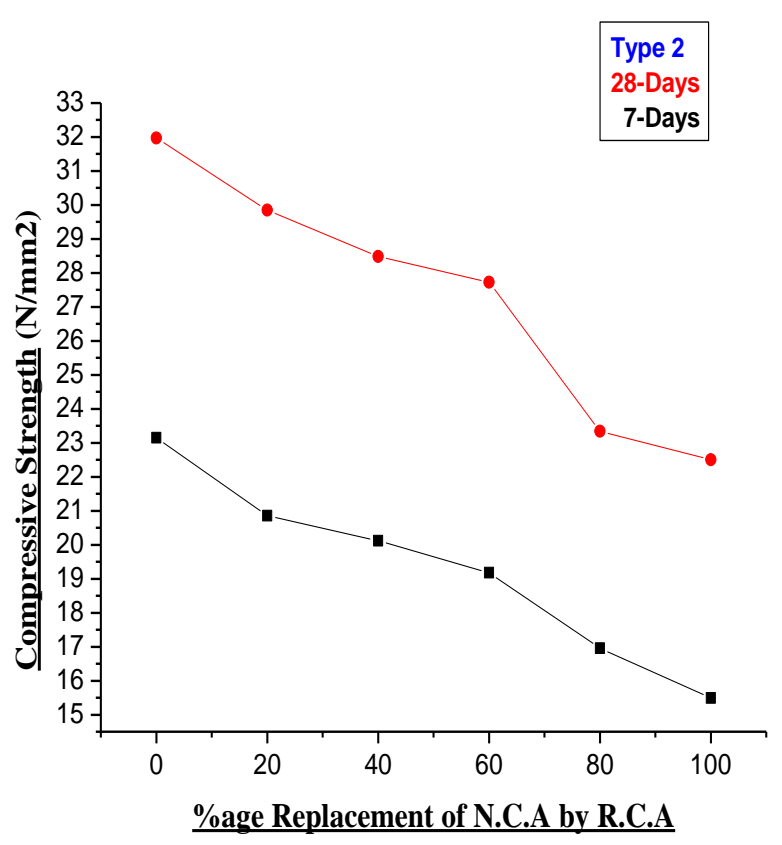

Fig 4.5: \% Replacement of N.C.A by R.C.A V/S Compressive Strength. 


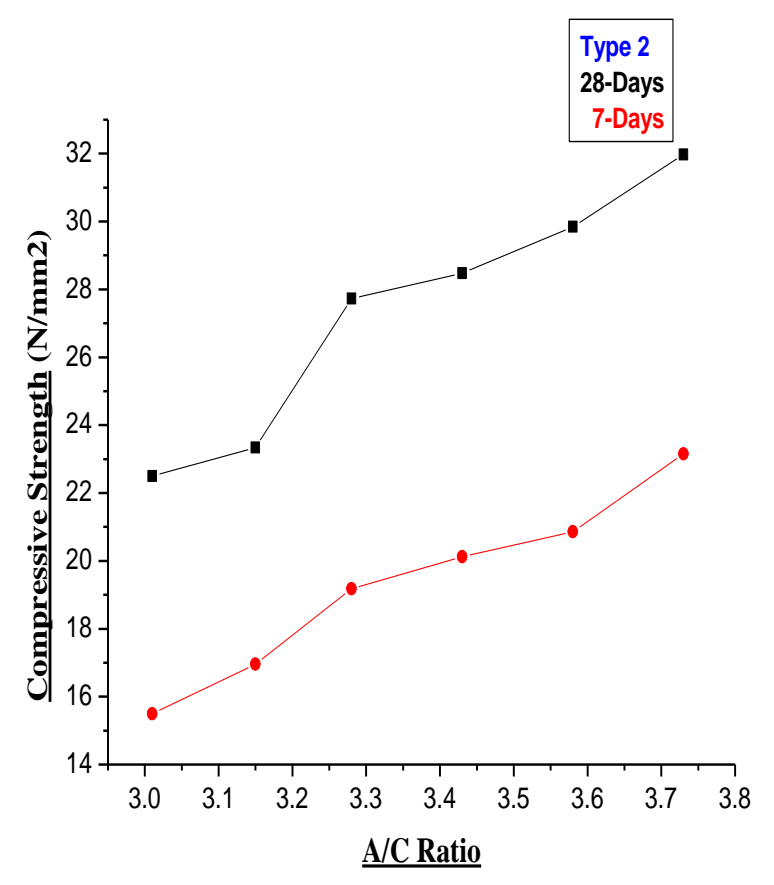

Fig 4.6: A/C Ratio V/S Compressive Strength.

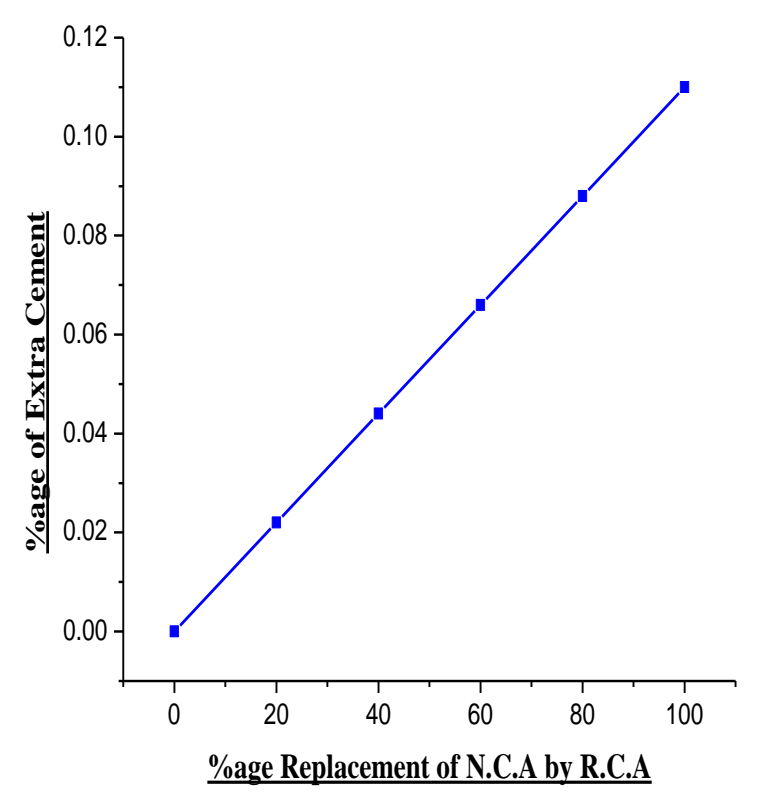

Fig 4.7: \%Replacement of N.C.A by R.C.A V/S \%age of Extra Cement.

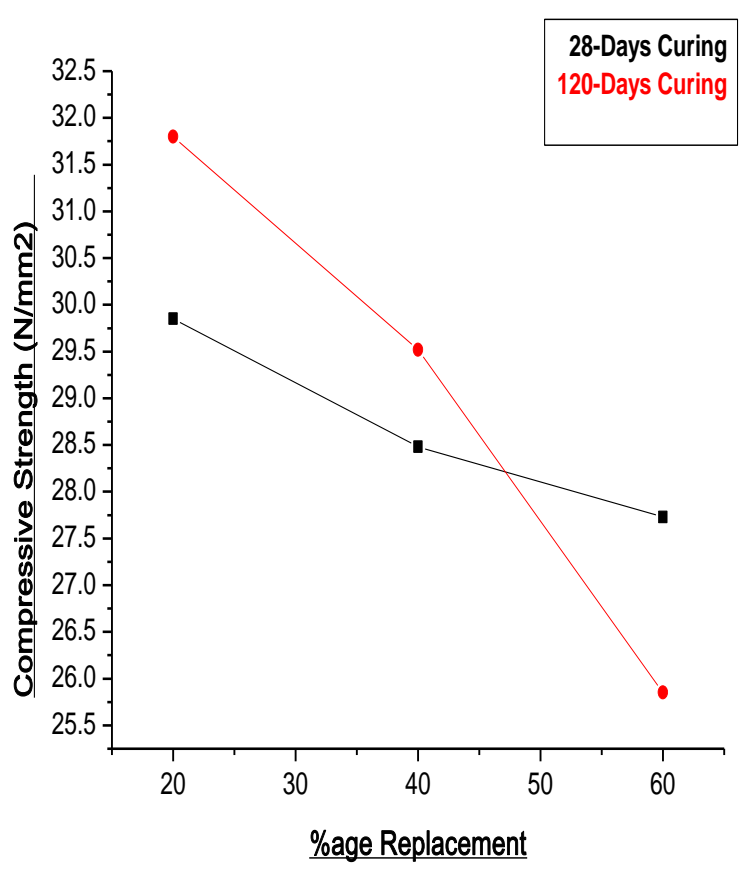

Fig 4.8: \%Replacement of N.C.A by R.C.A V/S Compressive Strength

\section{DISCUSSION}

The results of various experimental works which were carried out in the project work are given in section 4.1. Based on the obtained results, some of the salient points are discussed below.

1) In Type-1 concrete mix, the \%age replacement of N.C.A by R.C.A is done by an amount of $00.0 \%, 20 \%$, $40 \%, 60 \%, 80 \%$ and $100 \%$, but while designing the concrete mix, only the properties of N.C.A is considered rather than R.C.A.

In fig. 4.4 it is observed that, as the \%age replacement of N.C.A by R.C.A increases, the compressive strength for both 7-days and 28-days curing is decreasing. However from the curve for 28-days curing it is observed that, upto $40 \%$ replacement by R.C.A, the concrete had reached its target mean strength.

2) As in case of Type-1, here in Type-2 concrete mix also, the N.C.A are replaced by R.C.A by an amount of $0.00 \%, 20 \%, 40 \%, 60 \%, 80 \%$ and $100 \%$, but the correlation in the quantities of concrete ingredients which were obtained by the concrete mix design prepared by using the properties of N.C.A and R.C.A is made.

In fig. 4.5, the curve for 7-days and 28-days curing shows that, as the \%age replacement of N.C.A by R.C.A increases, the compressive strength is going on decreasing. However, upto $60 \%$ of replacement by R.C.A, the concrete had achieved its target mean strength. Sudden fall in compressive strength after $60 \%$ 
of replacement indicates that, as the quantity of R.C.A in the concrete mix increases, the water absorption capacity will also get increased and proportionally the workability of concrete will get decreased. Hence a sudden fall in the compressive strength is observed.

3) Referring fig. 4.6, it is observed that, the compressive strength is increasing, even after increase in $\mathrm{A} / \mathrm{C}$ ratio. This increase in compressive strength is due to the addition of extra quantity of cement for higher $\mathrm{A} / \mathrm{C}$ ratios.

4) In fig. 4.7, the $\%$ ages of extra cement to be added in case of R.A.C for achieving its target mean strength in given. Upto $60 \%$ of replacement by R.C.A, the concrete has achieved its target mean strength. Beyond $60 \%$ replacement, fall in compressive strength is observed, even after adding extra quantity of cement, this is mainly because of the aggregate crushing value of R.C.A is higher than that of N.C.A, hence as the quantity of R.C.A is increased in the concrete mix, the compressive strength is decreasing.

5) In the fig. 4.8 , by comparing the curve drawn for 120 days curing with 28 -days curve, it can be observed that, there in a little increase in compressive strength for $20 \%$ and $40 \%$ replacement. But for $60 \%$ of replacement, fall in compressive strength is observed. This fall in compressive strength is mainly because, as the percentage replacement increases, the rate of absorption of water by R.C.A will increases. Due to this higher rate of water absorption, the aggregates will get saturated with water, which leads to the decrease in compressive strength of R.A.C.

\section{CONCLUSION}

Based on the results and discussions given in the previous chapter, some of the conclusions drawn are as listed below.

1. From the concrete mix which is prepared by using the correlated properties of N.C.A and R.C.A, it can be concluded that, upto $60 \%$ replacement of N.C.A by R.C.A can be made, provided, $0.60 \%$ of extra quantity of cement is to be added in the concrete mix, for achieving its target mean strength.

2. During the initial stage of curing, the rate of development of compressive strength is very fast in case of R.A.C. In the middle stage i.e., in between 728days the rate of development of compressive strength is moderate. Beyond 28-days, the rate of development of compressive strength in almost nill.

3. In R.A.C with $20 \%$ replacement by R.C.A about $6.53 \%$ of higher compressive strength is obtained in later stage of curing i.e., beyond 120-days and with $40 \%$ replacement by R.C.A about $3.65 \%$ of higher compressive strength is obtained. But for $60 \%$ of replacement by R.C.A, there is a decrease in compressive strength by $6.77 \%$.

4. The concept of R.A.C can be used in concrete structural works of any grade, provided, additional percentage of extra cement is to be added for achieving the desired target mean strength of the concrete mine.

\section{REFERENCES}

[1] Alan o. Buck:'recycled concrete as a source of aggregate', american concrete institute journal, may 1977, vol.7, pp-213-219.

[2] Bcsj: 'study of recycled aggregate and recycled aggregate concrete', japan concrete journal, japan, vol.16, no.7, july 1978, pp-18-31.

[3] Frondiston-yannas s: 'waste concrete as aggregate for new concrete', American concrete institute journal, august 1977, vol.4, pp. 372-376.

[4] Malhotra v.m:'use of recycled aggregate as a new aggregate', proceeding of symposium on energy and resource conservation in the cement and concrete industry, canmei report 76-78, Ottawa, 1978.

[5] Rasheeduzzafar khan a: 'recycled concrete source of new aggregate', cement, concrete, aggregate journal [astm], vol.6, no.1, 1984, pp. 17-27.

[6] R. Raravindrarajah and c. T. Tom: 'properties of concrete made with crushed concrete as coarse aggregate', magazine of concrete research, vol.130, March 1985, pp.29-30.

[7] R. Ravindrarajah, loo y. H, and tom c. T: 'recycled concrete as fine and coarse aggregates in concrete', magazine of concrete research, vol.39, no.141, December 1987, pp-213-220. 